\title{
Textiles from orange peel waste
}

\section{Sachidhanandham Aishwariya*}

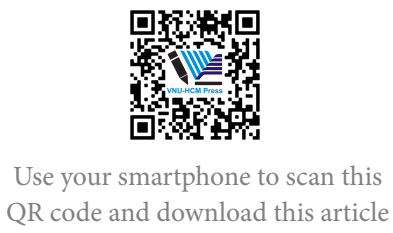

DST-INSPIRE Fellow \& Assistant Professor; Department of Textiles and Clothing, Avinashilingam Institute for Home Science and Higher Education for Women, Coimbatore, India

\section{Correspondence}

Sachidhanandham Aishwariya, DST-INSPIRE Fellow \& Assistant Professor; Department of Textiles and Clothing, Avinashilingam Institute for Home Science and Higher Education for Women, Coimbatore, India

Email: aishu55@gmail.com

History

- Received: 2019-11-25

- Accepted: 2020-04-20

- Published: 2020-06-01

DOI : 10.32508/stdj.v23i2.1730

\section{Check for updates}

\section{Copyright}

(c) VNU-HCM Press. This is an openaccess article distributed under the terms of the Creative Commons Attribution 4.0 International license.

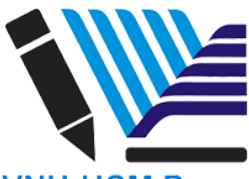

\begin{abstract}
The global textile business is now gearing towards greener alternatives to combat pollution and avoid synthetics in production. Ironically, there is an increased awareness among consumers on the quality of the product and choices they make in their shopping. The natural and synthetic fibres have set limitations, which has made manufacturers look out for other alternative fibres. Bamboo, banana, milk, and corn are experimented for its commercial capabilities to perform as a textile material. To add on to the list, orange, the popular, and the most preferred fruit are known for its refreshing flavour. The peels after consumption/ processing of the fruit are discarded in the landfill, which is an organic waste with immense potential. This paper details the successful brand 'Orange fibre', its journey from scratch, and the properties of textiles made from processing orange peel waste. The current areas of research have also been covered in a brief way, to invite more scholars to create solutions for the hitherto pollution orange peel waste.

Key words: orange peel waste, organic waste, sustainable textiles, eco-friendly fibres, renewable fibres, regenerated cellulose, orange fiber
\end{abstract}

\section{INTRODUCTION}

Natural fibres like cotton, silk, and wool were utilized for the maximum by humans to a maximum possible timeline. Nineteenth-century proposed the replacement of natural fibres with synthetics with excellent performance properties that ruled for another hundred years now ${ }^{1}$. The petrochemical-derived fibres like polyester are a source of micro-plastic pollution, non-bio-degradable, toxic, and a threat to humans. Today, agriculture wastes and other organic wastes are seen as a potential renewable, biodegradable material to be made into textiles ${ }^{2}$.

\section{POPULARITY OF ORANGES}

Orange production is approximately 51.8 million metric tonnes in $2014^{3}$. The commonly consumed fruits worldwide are banana, apple, grapes, strawberry, and orange. In many countries, orange juice is an essential entity in breakfast to cater to the everyday recommended dose of vitamin C. Oranges are the richest source of vitamins, minerals, and energy, which has the ability to give an instant refreshment ${ }^{4}$. The regular consumption of orange helps in the effective functioning of the heart, kidney, and aids infertility. There are other health benefits for skin, teeth, and bone, along with maintaining the normal blood pressure and cholesterol levels in the body ${ }^{5}$. Orange is one of the varieties in citrus fruit family, and other popular ones include lemon, mosambi, sweet lime, mandarins, and grapefruit. Nearly seventy percent of the orange fruits are used in the food processing industry for making juice, jam, syrups, sweets, pectin, flavonoid, and fibres. It is also used in making refreshing drinks to induce smell, flavor, energy, and color. The list of uses for the fruit goes endless, whereas the peel that is a by-product of processing has fewer recycling options. For instance, the lemon peel is used to extract pectin and some varieties of citrus fruit for making cosmetics ${ }^{6}$.

The top producers of orange are Brazil, USA, India, China, Mexico, Spain, Egypt, and Italy. Brazil produces 1.8 million tonnes of orange per year. Approximately $15-25$ million tonnes of peel waste are found on landfill without recycling or composting. The transported waste is thrown in landfills or incinerated. These peels dumped on a site can be a threat to the environment and human health. They may decompose, give away foul odour, microbial infestation, attract flies, and risk of spreading diseases during the rainy season. The baseline is the huge tonnes of orange peel waste is a menace. Two ecologists Daniel Janzen and Winnie Hallwachs in 1997, dumped 12,000 tonnes of orange peel over degrading lifeless soil in Amazon (Figure 1 ). The selected area was a victim of burning trees in the forest for installing oil refineries. Sixteen years later, when the couple returned, they were amazed by the bio-diversity, rich landscapes, biomass that are a result of citrus peel waste ${ }^{7}$. This is an example to insist on the power of organic waste. 


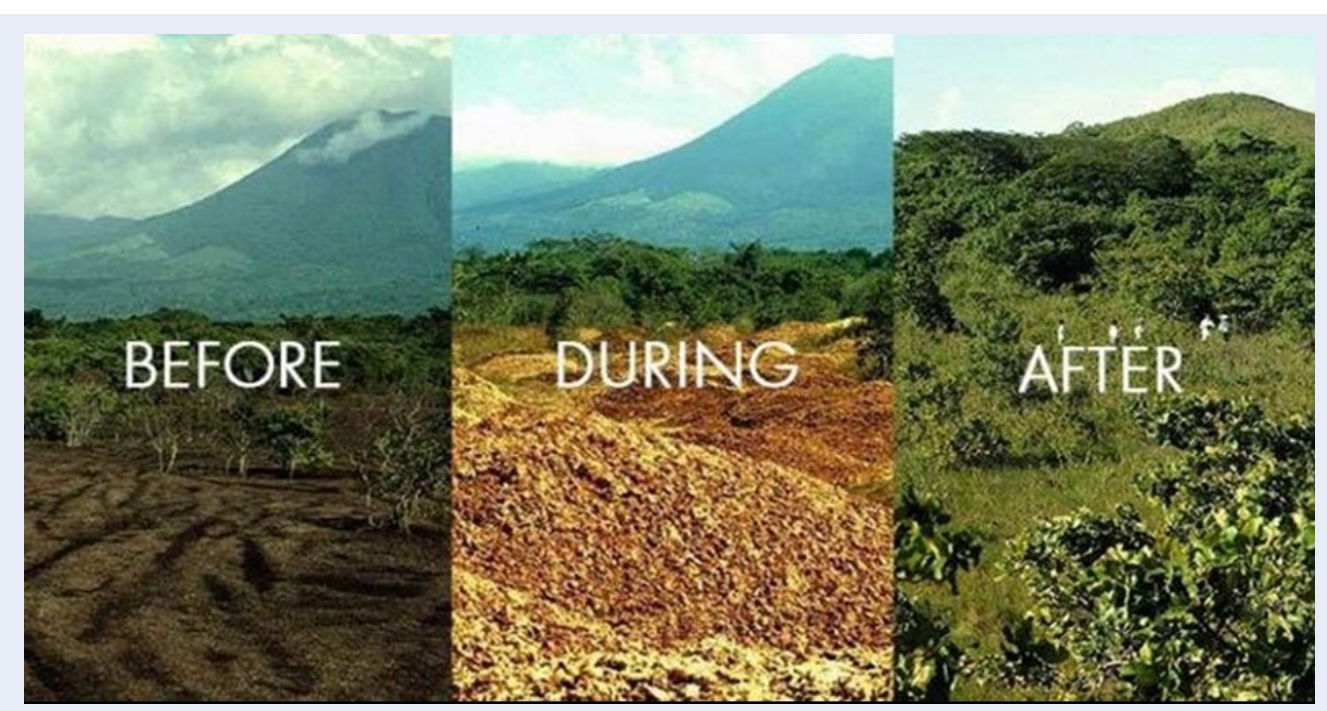

Figure 1: Amazon rainforest before-during and after dumping the orange peel waste. The organic waste turned into compost and returned the soil nutrients making it fertile vegetation once again.

\section{TEXTILES FROM ORANGE PEEL WASTES - INVENTION}

Textile is the second largest polluting industry in the world. There are many factors that contribute to pollution by the textile industry from cultivation, processing, shipping, and consumption (Figure 2 ). World bank has estimated $20 \%$ of water pollution is caused by the textile processing industry working on the dyeing and finishing of fabrics ${ }^{8}$. The excessive consumption of freshwater, discharging pollutants in the water bodies, chopping down trees for fuel, utilising large tons of oil for production, release of micro plastics into ocean and dumping of textiles on landfills the thread is long. There are different types of organic waste that are specific to that region and available in abundance after cultivation or processing, it is important to experiment such wastes for its potentialities.

In 2012, Adriana Santanocito, a native of the Sicilian city of Catania, found a similar organic waste from her city which was popular as the largest consumer of orange as juice. On further research, she found that globally, 7,00,000 tons of citrus peel waste every year are thrown away in landfills without proper recycling alternatives (Figure 3 ). She decided to conduct a pilot study to convert the peel into textiles for her university project. The grounded orange peel waste was then processed, and cellulose was separated. This was further sent to a spinning industry in Spain for making the yarn. This is blended with silk and cotton to make satin and poplin material ${ }^{9}$. They also make fabrics from $100 \%$ orange peel waste fibre which is similar to viscose (textile made from wood-also called rayon) available in light shades that can be dyed, printed, and even washed like other conventional materials. The fabric was sold at $€ 30$-€40 per meter.

Enrica Arena, the hostel mate of Adriana, who assisted in documenting the research to be drafted in English, joined the research soon after (Figure 4 ). Fabric made using orange peel waste textiles was resembling silk in terms of quality, softness, shiny surface, and colour. Nanotechnology and microencapsulation were employed to retain the beneficial properties of citrus fruits on to fabric and the technologyaided in maintaining these properties till 20 washes. The biodegradable material was good to be blended with cotton, silk, elastane, and pineapple. The duo decided to present this in various forums to demand, scope and market for the developed textile ${ }^{10}$.

\section{ORANGE FIBRE - THE BRAND}

Adriana Santanocito and Enrica Arena collected orange peel waste from the local juice makers in the city and washed, cleaned, processed them. The orange peel waste is processed with their patented technology 'Pastazzo', that separates the cellulose from the material $^{11}$. This will be then mixed with material and made into a filament, which can be used for weaving or knitting, as $100 \%$ orange peel waste fabric, or a blend with cotton and polyester. The company sells three types of fabrics, lace silk in black and white, cream coloured satin, and viscose like daily wear fabric. The inventors won the Global Change Award 
$20 \%$ of Industrial pollution is from textiles

1 kilogram of cotton cultivation uses three kilograms of chemicals

6.6. kgs of silkworms are killed to make one kg of silk (Pulse of Fashion Industry Report 2017)

20,000 litres of water is used to make one kilogram of cotton

Dyeing one ton fabric requires 200 tonnes of fresh water

8000 chemicals go into making a garment from raw to final product

$1,90,000$ tons of microplastics goes into the water bodies through textile industry

$90 \%$ of untreated textile effluent water is discharged into oceans

70 million barrels of oil is used to make polyester

70 million trees are cut down each year to make fabrics

80 billion textiles and clothing pieces go to landfills every year

Figure 2: Facts Sheet on Textile Pollution.
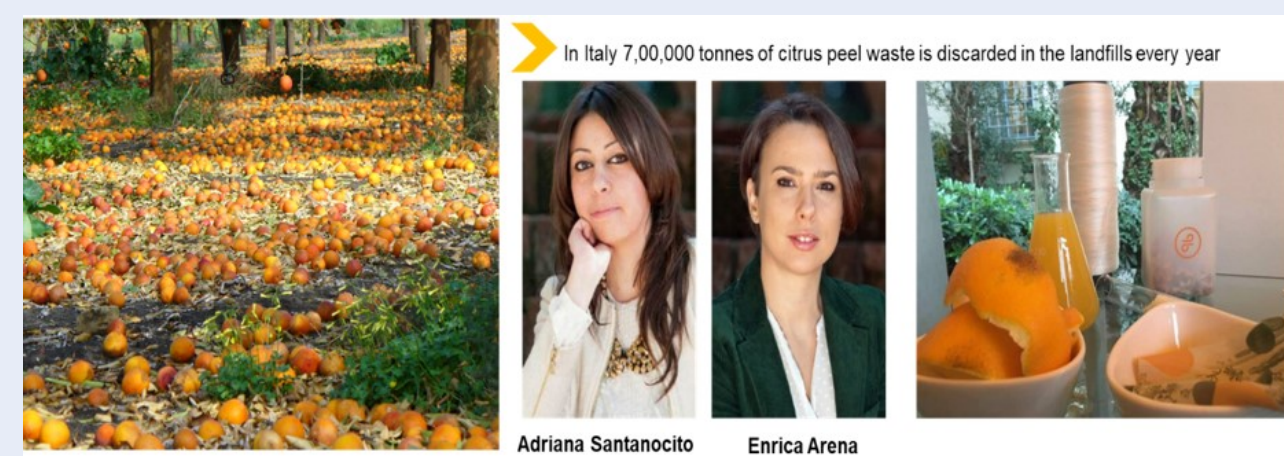

Adriana Santanocito

Enrica Arena

Figure 3: Processing of Orange peel waste into textiles (Pollution, Inventors, Process).

2015, which had around 2,700 inventors from 112 countries presenting their work. On winning, they received huge funding through which they installed their large-scale plant to prepare regenerated cellulose from orange peel. Sooner, their commercial production branded "Orange Fibre" with a tagline 'Sustainable and vitaminic textiles from citrus waste' was launched ${ }^{12}$. Further recharging methods with special fabric softeners experimented. Their company received many awards during their journey (Figure 5 ). Their patented idea was purchased by international brand H\&M. It was the first brand in the world to launch textiles made from orange peel waste under the category, "Conscious Exclusive line - 2019”. A bohoinspired top in collaboration with BLOOM foam algae was also in the series of collections. Victoria Albert Museum in London organized on an exhibition displaying 300 works on the title 'Fashion from Nature', displaying over 300 garments along with the Ferragamo Orange Fibre Collection (Figure 6 ). Citrus peel and pineapple leaf fibre were combined with Italian silk and embroidered with vegan material. Salvatore Ferragamo, the Italian Designer, created high-end shirts, dresses using orange fibre and many designs that they launched as Capsule collection on Earth day (Figure 6 ). In order to expand their produc- 

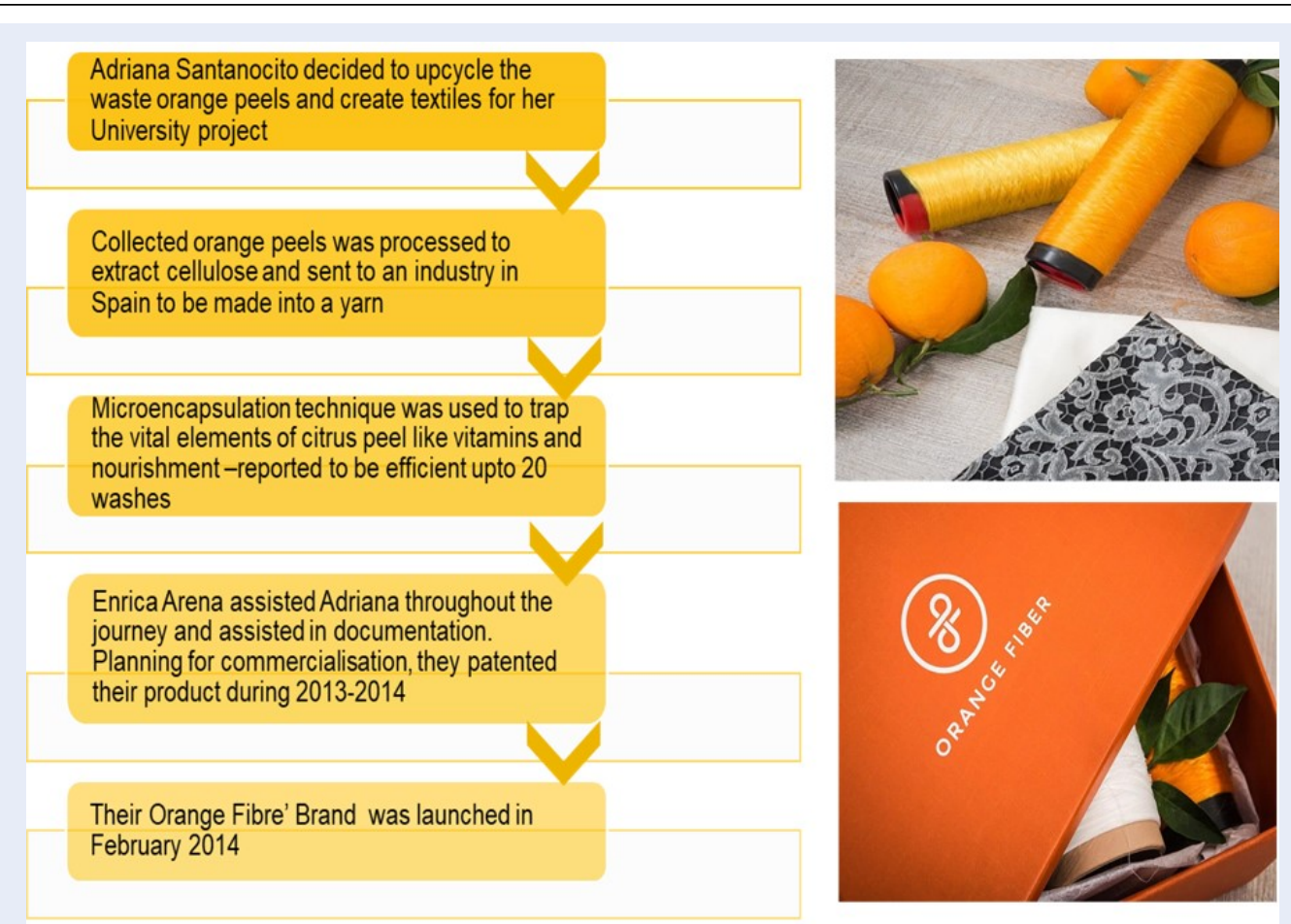

Figure 4: Journey of orange peel waste into textile (Orange Fibre brand).

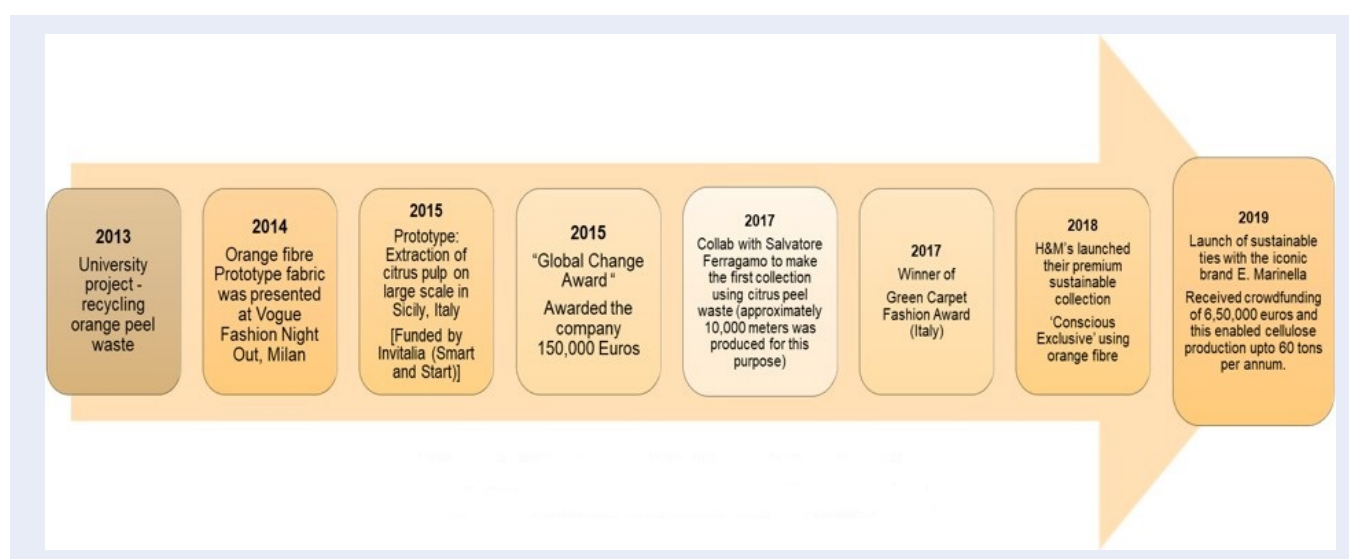

Figure 5: Milestones of Orange Fibre Brand (Sustainable and Vitaminic textiles from citrus waste).

tion, they arranged for a crowdfunding campaign in 2019 to get 2,50,000 Euros and surprisingly received $6,50,000$ Euros $^{13}$. This initiated the large-scale production of more than 60 tons of cellulose per year. In a nutshell, we can conclude that fruit textiles received a good reception from consumers worldwide for its eco-friendly nature, biodegradability and sustainability. The journey and recognitions received are given in the figure below.

\section{GOODNESS IN TEXTILES MADE FROM ORANGE PEEL WASTE}

Textiles are rightly called as second skin due to its close positioning to the body, whatever is placed over the skin affects the health of the person by releasing the contents into the bloodstream. Synthetic chemicals of organically derived materials are definitely a choice considering the health benefits for an individual. Fabrics made from orange peel waste have been proved to perform like vitamin $\mathrm{C}$ infuser along with 

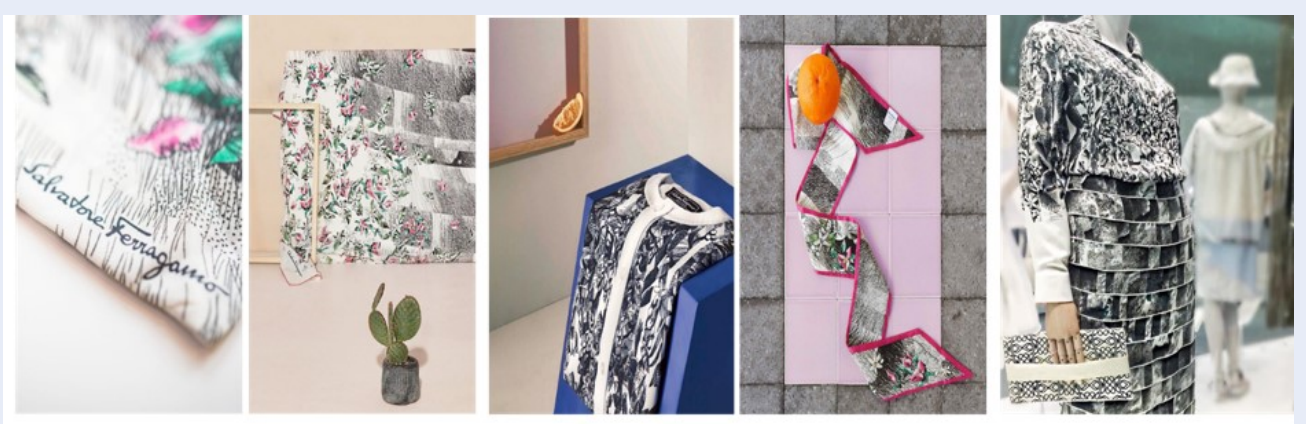

Figure 6: Ferragamo Collection made using orange peel waste and pineapple leaves.
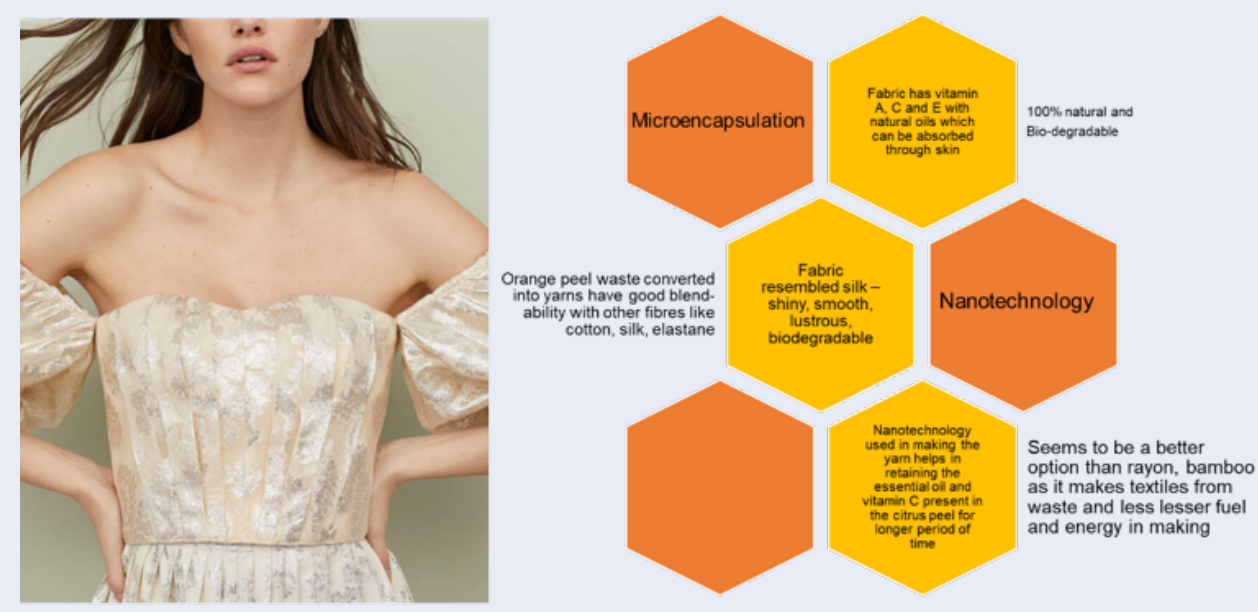

Figure 7: Properties of textiles made from orange peel waste.

moisturizing capabilities. The natural oils of orange peel are retained in the fabric and are believed to give nourishment to the skin. The amazing quality of orange fiber can be its rich source of vitamin $\mathrm{C}$ and essential oils that can be like a moisturizing cream on the skin. The reduced carbon footprint by using a material that could be an organic waste dumped on landfills is reverse engineered into a material of value and utility (Figure 7 ). In order to make the clothing more affordable, a blend with yarns made from pineapple leaf. The blend-ability of orange fibre with cotton, silk, elastane is good; hence the product range is also diversified with a prospective future.

\section{CURRENT USES OF ORANGE PEEL WASTE}

Orange peel waste can be collected on a domestic scale, large scale from juice vendors or food processing industry. It can be imported or exported to other places for recycling the waste into beneficial products, and there are trade websites that sell orange peel waste for $50 \$-450 \$$ for 100 tonnes. The existing options are not sufficient, considering the expected increase in the future, which unveils the research gap to be filled by future scholars.

\section{Oil extraction}

Food and agricultural organization of the United States suggests that 1.3 billion tonnes of food are wasted in which citrus peel wastes are also enlisted. Thus, exploring new alternatives is essential. One such was the study on extraction of oil from the citrus peel waste using hydro-distillation, steam distillation, ultra-sound, microwaves, super-critical-carbondi-oxide, enzymes, and a combination of technologies. The essential oil from oranges has various bioactive compounds like limonene, $\mathrm{p}$ - myrcene, sabinene, b-pinene, and linalool that will make it a product of great value ${ }^{6}$. Another study processed citrus peel waste to produce ellagic acid through the submerged 
fermentation, that enables in the biotransformation of the molecules which can be used as an antioxidant and antibacterial agent ${ }^{14}$. In most cases, citrus waste is dried and powdered. One report highlighted that hot air impingement drying is a very effective technique for drying orange peel waste and $65^{\circ} \mathrm{C}$ is the best for protecting the quality of polyphenols, ascorbic acid as well as antioxidant properties ${ }^{5}$.

\section{Dyeing}

Dyes from orange peel was the obvious first level research. The orange peel waste can be collected and used fresh or sundried. The boiling of peels releases a light orangish-yellow colour to the water. Suitable mordant can be added to hold the dye on to the fabric. The resultant fabric had a light shade of yellow along with a sweet citrus smell. In addition, it had mild fragrance, anti-microbial, antioxidant, and astringent properties on to the fabric, which can be retained up to twenty washes. The colour fastness and wash fastness property were good. It was a suggestion recommendation for functional clothing and sports textiles ${ }^{15}$. A study done using wasted peels of orange and lemon with alum and sodium carbonate $(30 \%$ mordants) gave good quality in shade and fastness. A trial study was done to isolate pectic acid from citrus peel waste by acid hydrolysis. This was mixed with a thickening agent and used as a printing paste to print designs on textiles. There is a study reported with sodium alginate that showed better dye take up, brightness in shade and wash fastness ${ }^{16}$.

\section{Anti-microbial finishing}

Grinded orange peels are used a textile finishing agent. A study quoted that the extracts from citrus (lemon and orange) peel waste combined with sodium bicarbonate, coated on a cotton fabric resulted in appreciable anti-odour and anti-microbial properties on the fabric. These are very significant entities in medical textiles. It is also reported that the friction occurred during washing was found to have negative impact on the finishing given by decreasing the efficacy of the active agents and their antimicrobial activity. The use of an alkaline binder however, has resulted in better performance properties. It was also interesting to note that the finished fabric sustained all microbes except C. Albicans ${ }^{16}$. Another work reported orange peel and papaya skin with silver nanoparticles combined to induce anti-microbial character to the fabric ${ }^{17}$.

\section{Mosquito-repellent finish}

These citrus peel help in eliminating deadliest bug on the planet, mosquitos. The collected peel dried, powdered and coated on the fabric using padding mangle was found to perform as an effective mosquito repellent fabric. The active extracts of limonene extracted from orange peel using the ultrasonic waves were converted into micro-capsules (microencapsulation) and further coated on the cellulosic fabric for better insect repellent property. The fabric testing showed very good results for UV protection, self-cleaning, antimicrobial/antioxidant properties ${ }^{18}$.

\section{Print transfer medium}

In 2018, a group of IIT-Hyderabad scholars under the guidance of Prof. Chandra Shekhar Sharma published research, which quoted a lack of commercial utilities for orange peel waste. They have suggested that the material can be used as an insulating material in building construction, a remedy for the oil spill, source of carbon. Limonene is a special material present on the citrus peel, which can be isolated for various utilities, but the process of extraction is expensive. The extract from the citrus peel has a unique property to transfer ink from one surface to another and thus can be a good print transfer medium. Transfer of prints can be done on a variety of surfaces like wood, mica, paper, clothes, glass, human skin (for tattoos) to extract the design. During their course of experimentation, they found three layers in the orange peel extract

- The top layer of oil: used in polystyrene recycling,

- Second cellulosic layer: can be converted to carbon and used as an electrode in batteries.

- Water-like bottom layer: natural solvent for biopolymers to produce nano-fibres ${ }^{19}$.

\section{Water purification}

In 2014, Dr. Justin Chalker and his team working in Synthetic Chemistry, Flinders University, developed a polymer with orange peel and sulfur (a by-product of the petroleum industry), which was effective in removing mercury from water. The developed polymer was suggested to be given as a coating inside the pipes to remove mercury. In a study, the orange peel was combined with Calotropis procera leaves, sawdust, and coconut shells to remove iron from wastewater (after the activation process) ${ }^{20}$. 


\section{Textile effluent wastewater}

Orange peel has pectin, hemicellulose, lignin, and limestone, which can be used as an effective dye adsorbent, remove toxins and organic pollutants from the textile effluent water. The study on principles of Green Chemistry suggests that orange peel is effective in reducing $\mathrm{pH}$, colour, and COD (Carbon-dioxide demand) in the textile effluent water. Orange peel waste fibres are proved to have the property to absorb toxic dye particles from the aqueous medium, and also in removal of specific dyes like Acid violet $17^{21}$, burgundy-16 can also be seen. Magnetized orange peel powder has been tested as a dye adsorbent to confiscate crystal violet dye from the aqueous solution of textile effluent water. In the process, external magnets are used to take back the magnetic particles after adsorption. It is an interesting study that compares with and without magnets along with the citrus peel. The high adsorption affinity, separability, regenerability, cost-effectiveness makes the technique of magnets induced orange peel to be a good remedy to remove crystal violet from effluent water ${ }^{22}$. Research publications suggest the role of citrus peel waste to decolour the effluent in the carpet industry and the combination of citrus peel and banana peel for acting as a dye adsorbent. Studies were done on utilizing activated carbon along with orange peel waste to treat effluent water $^{23-25}$.

\section{Bio-adsorbent}

At the industrial level, the role bio-adsorbent is well known. There are studies where the citrus peel is of orange peel waste as a converted into a bio-adsorbent (oil adsorbent medium) to combat oil spills in the ocean. Orange peel waste as bio-adsorbent is effective; however, low $\mathrm{pH}$, contact time, high concentration, bio-sorbent mass can also influence the rate of adsorption. Design and development of wipes for kitchen and oil spills are also possible using the orange peel wastes ${ }^{26}$.

\section{Biogas}

Experiments on the production of biogas from waste orange peels are also popular. Organic waste can be treated using a). mono-treatment scenarios (pyrolysis, incineration, and anaerobic mono-digestion), b).co-treatment (four anaerobic co-digestion strategies using animal manure and seaweed) and c). traditional non-energy focused handling techniques (landfilling, composting, and animal feeding), among which the co-digestion technique was found to be top rated as a result of trials conducted in the study ${ }^{27,28}$.

\section{Bio-char}

Orange peels can be used like animals, fertilizer, and feedstock. Recently a study suggested synthesis of biochar, high in carbon (65-90\%), and porous. The collected wastes were processed by the use of thermochemical energy. The resultant biochar can be used as a soil amendment to restore nutrients, as adsorbents to remove chemicals like ammonium, led, and other ionic compounds from water. It can be used as a catalyst in syn-gas production, as bio-composite, and in the production of biofuel ${ }^{29}$.

The very interesting paper on the life cycle assessment of orange peel waste unveils that the commonly available recycling options are composting, animal feeding, or landfill disposal ${ }^{30}$. Commercially successful energy conservation and resource utilization techniques are still void. Pyrolysis, incineration, anaerobic mono-digestion and co-digestion (animal manure and seaweed) given the choices, the latter was found to be the best way to handle the waste with nitrate leaching into the soil being one of the drawbacks ${ }^{31}$.

\section{FUTURE PERSPECTIVE FOR TEXTILES FROM ORANGE PEEL WASTE}

There are ongoing researches using orange peel waste to be used for the synthesis of porous carbon using copper carbonate as an activation agent and develop supercapacitors with high power and energy density $^{32}$. Another research paper indulged in reporting the study on developing Fe-modified hydrochar from orange peel waste, optimize and characterize the protocols like dose, temperature, time, concentration, and identify the dominant mechanisms through kinetic analysis. Orange peel waste was hydrothermally carbonized after eight hours at $200{ }^{\circ} \mathrm{C}$, and the resultant hydrochar was embedded with magnetite nanoparticles ${ }^{33}$. Textiles from recycling orange peel waste are considered to be a sustainable alternative as it uses a lesser carbon footprint compared to conventional textile production. Handmade paper making from agricultural wastes is gaining momentum. The brand 'Crush', is actively involved in making papers from grapes, cherries, orange peel, almond skin, lavender, coffee dust, corn, olives, kiwis, and hazelnuts. Thus, paper making can be one of the ecofriendly solutions to hitherto polluting waste. Cellulose has an amazing quality, and textiles made from them are known for softness, dye absorbency, and breathability.

In a nutshell, the orange peel waste can be used as cattle feed, manufacturing of handmade paper, compost, 
as a soil amendment, perfumes, cosmetics, essential oil, textile dyeing, printing, print transfer medium, and for fragrance finishing, mosquito repellent, antimicrobial finishing on textiles. It is also used in polystyrene production, limonene extraction, purifying water, treating textile effluent wastewater, as bioadsorbent and as a source of carbon, biochar, and biofuel. This paper demonstrates a few existing remedies for orange peel waste, which can open up more possibilities in the future.

\section{CONCLUSION}

The recent threat by the textile industry is the invasion of plastics (as microplastics) into the ocean by the use of synthetic textiles in our everyday life. It is found that polyester, nylon, acrylic make $60 \%$ of clothing and release microplastic during processing, walking, and washing. A study done on washing and microfibers generation reported a release of 7,00,000 fibres in washing, 1,900 fibres in case of one synthetic garment, and 1 million fibres during laundering of fleece. Today, $73 \%$ of fishes in the ocean is reported to have microplastics in their stomach, which can enter the human food chain. It is studied that $35 \%$ of microplastics in the ocean come from the textile industry (2017 International Union for Conservation of $\mathrm{Na}$ ture) The used cups and straws being banned now the identity is shifted to textiles made from petrochemicals $^{34}$. This synthetic debris should seize, and more sustainable materials should enter the supply chain to create sustainable clothing.

\section{CONFLICT OF INTEREST}

The authors have declared that no competing interests exist.

\section{REFERENCES}

1. Aishwariya S. Waste Management Technologies in Textile Industry. Innov Energy Res. 2018;07:175-179. Available from: https://doi.org/10.4172/2576-1463.1000211.

2. Aishwariya S, Amsamani S. Exploring the Potentialities and Future of Biomass Briquettes Technology for Sustainable Energy. Innov Energy Res. 2018;07. Available from: https://doi. org/10.4172/2576-1463.1000221

3. Kadam AA, Sharma B, Saratale GD, et al. Super-magnetization of pectin from orange-peel biomass for sulfamethoxazole adsorption. Cellulose. 2020;27:3301-3318. Available from: https: //doi.org/10.1007/s10570-020-02988-z.

4. Wang M, Shi R, Gao M, et al. Sensitivity fluorescent switching sensor for $\mathrm{Cr}(\mathrm{VI})$ and ascorbic acid detection based on orange peels-derived carbon dots modified with EDTA. Food Chem. 2020;318:126506. PMID: 32126473. Available from: https:// doi.org/10.1016/j.foodchem.2020.126506.

5. Deng LZ, Mujumdar AS, Yang WX. Hot air impingement drying kinetics and quality attributes of orange peel. J Food Process Preserv. 2020;44:1-11. Available from: https://doi.org/10.1111/ jfpp.14294.

6. Gavahian M, Chu YH, Khaneghah AM. Recent advances in orange oil extraction: an opportunity for the valorisation of orange peel waste a review. Int J Food Sci Technol. 2019;54:925932. Available from: https://doi.org/10.1111/ijfs.13987.
7. Dockrill P. How 12,000 Tonnes of Dumped Orange Peel Grew Into a Landscape Nobody Expected to Find. 2017;Available from: https://www.sciencealert.com/how-12-000-tonnesof-dumped-orange-peel-produced-something-nobodyimagined.

8. Periyasamy AP, Ramamoorthy SK, Rwawiire YZS. Sustainable Wastewater Treatment Methods for Textile Industry. Springer Nat Singapore Pte Ltd. 2018;Available from: https://doi.org/10. 1007/978-981-10-8591-8.

9. Favini tells the story of Orange Fiber. In: Sustain Channel;Available from: https://www.favini.com/en/news/favinitells-the-story-of-orange-fiber/.

10. Yamamori N. Dress yoursefff in orange fiber. In: Conscious Welum. Accessed 19 Apr 2020. 2017;Available from: https: //www.welum.com/article/dress-yourself-with-oranges/.

11. Maria A, Santaocito EV. Production of textile from citrus fruit. 2013;.

12. Fabrics from Oranges - interesting and exciting. In: Unnati silks. Accessed 19 Apr 2020;Available from: https://www.unnatisilks.com/blog/fabrics-from-orangesinteresting-and-exciting/.

13. Boztas S. Nice threads: the waste-based fibres cleaning up fashion. In: Guard. Accessed 19 Apr 2020. 2018;Available from: https://www.theguardian.com/business- to-business/2018/feb/ $12 /$ nice-threads- the-waste- based-fibres-cleaning-up-fashion.

14. Sepúlveda L, Laredo-Alcalá E, Buenrostro-Figueroa JJ, et al. Ellagic acid production using polyphenols from orange peel waste by submerged fermentation. Electron J Biotechnol. 2020;43:1-7. Available from: https://doi.org/10.1016/j.ejbt. 2019.11.002.

15. Kumar CSS, Dhinakaran M. Extraction and Application of Natural Dyes From Orange Peel and Lemon Peel on Cotton Fabrics. Int Res J Eng Technol. 2017;4:2008-2009.

16. Amanuel L. Extraction of Pectic Acid from Citrus Fruit Peels and its Application as Textile Printing Thickener. Latest Trends Text Fash Des. 2018;1:45-50. Available from: https://doi.org/ 10.32474/lttfd.2018.01.000111.

17. Rani N, Jajpura L, Butola BS. Ecological Dyeing of Protein Fabrics with Carica papaya L. Leaf Natural Extract in the Presence of Bio-mordants as an Alternative Copartner to Metal Mordants. J Inst Eng Ser E. 2020;Available from: https://doi.org/ 10.1007/s40034-020-00158-1.

18. A AG, A AS. Efficacy of orange peel as a mosquito repellent. 2017;3:143-146.

19. Yadav S, Sharma CS. Novel and green processes for citrus peel extract: a natural solvent to source of carbon. Polym Bull. 2018;75:5133-5142. Available from: https://doi.org/10.1007/ s00289-018-2310-5.

20. Dwivedi P, Vijayakumar RP, Chaudhary AK. Synthesis of UMCNO-cotton fabric and its application in waste water treatment. Cellulose. 2020;27:969-980. Available from: https: //doi.org/10.1007/s10570-019-02840-z.

21. Sivaraj R, Namasivayam C, K K. Orange peel as an adsorbent in the removal of Acid violet 17 (acid dye) from aqueous solutions. Waste Manag. 2001;21:105-110. Available from: https://doi.org/10.1016/S0956-053X(00)00076-3.

22. Ahmed M, Mashkoor F, Nasar A. Development, characterization, and utilization of magnetized orange peel waste as a novel adsorbent for the confiscation of crystal violet dye from aqueous solution. Groundw Sustain Dev. 2020;10:100322. Available from: https://doi.org/10.1016/j.gsd.2019.100322.

23. Khaled A, Nemr AE, El-Sikaily A, Abdelwahab O. Treatment of artificial textile dye effluent containing Direct Yellow 12 by orange peel carbon. Desalination. 2009;238:210-232. Available from: https://doi.org/10.1016/j.desal.2008.02.014.

24. Nguyen TXT. Preparation, micro-structure and mechanical properties of porous carbonate apatite using chicken bone as raw material. Sci Technol Dev J. 2020;22:365-369. Available from: https://doi.org/10.32508/stdj.v22i4.1218. 
25. Abdurrahman FB, Akter M, Abedin MZ. Dyes Removal From Textile Wastewater Using Orange Peels. Int J Sci Technol Res. 2013;2:47-50.

26. Temesgen F, Gabbiye N, Sahu O. Biosorption of reactive red dye (RRD) on activated surface of banana and orange peels: Economical alternative for textile effluent. Surfaces and Interfaces. 2018;12:151-159. Available from: https://doi.org/10. 1016/j.surfin.2018.04.007.

27. Wikandari R, Nguyen $\mathrm{H}$, Millati R, et al. Improvement of biogas production from orange peel waste by leaching of limonene. Biomed Res Int 2015. 2015;Available from: https://doi.org/10. $1155 / 2015 / 494182$

28. Rokaya B, Kerroum D, Hayat Z, et al. Biogas production by an anaerobic digestion process from orange peel waste and its improvement by limonene leaching: Investigation of $\mathrm{H} 2 \mathrm{O} 2$ pre-treatment effect. Energy Sources, Part A Recover Util Environ Eff. 2019;00:1-9. Available from: https://doi.org/10.1080/ 15567036.2019.1692975.

29. Adeniyi AG, Ighalo JO, Onifade DV. Biochar from the Thermochemical Conversion of Orange (Citrus sinensis) Peel and Albedo: Product Quality and Potential Applications. Chem Africa. 2020;Available from: https://doi.org/10.1007/s42250-
020-00119-6.

30. Negro V, Ruggeri B, Fino D, Tonini D. Life cycle assessment of orange peel waste management. Resour Conserv Recycl. 2017;127:148-158. Available from: https://doi.org/10.1016/j. resconrec.2017.08.014.

31. Sial TA, Lan Z, Khan MN, et al. Evaluation of orange peel waste and its biochar on greenhouse gas emissions and soil biochemical properties within a loess soil. Waste Manag. 2019;87:125-134. Available from: https://doi.org/10.1016/j. wasman.2019.01.042.

32. Wan L, Chen D, Liu J, et al. Facile preparation of porous carbons derived from orange peel via basic copper carbonate activation for supercapacitors. J Alloys Compd. 2020;823:153747. Available from: https://doi.org/10.1016/j. jallcom.2020.153747.

33. Çatlıoğlu FN, Akay S, Gözmen B, et al. Fe-modified hydrochar from orange peel as adsorbent of food colorant Brilliant Black: process optimization and kinetic studies. Int J Environ Sci Technol. 2020;17:1975-1990. Available from: https://doi.org/ 10.1007/s13762-019-02593-z.

34. Resnick B. More than ever, our clothes are made of plastic. Just washing them can pollute the oceans. In: Vox; 